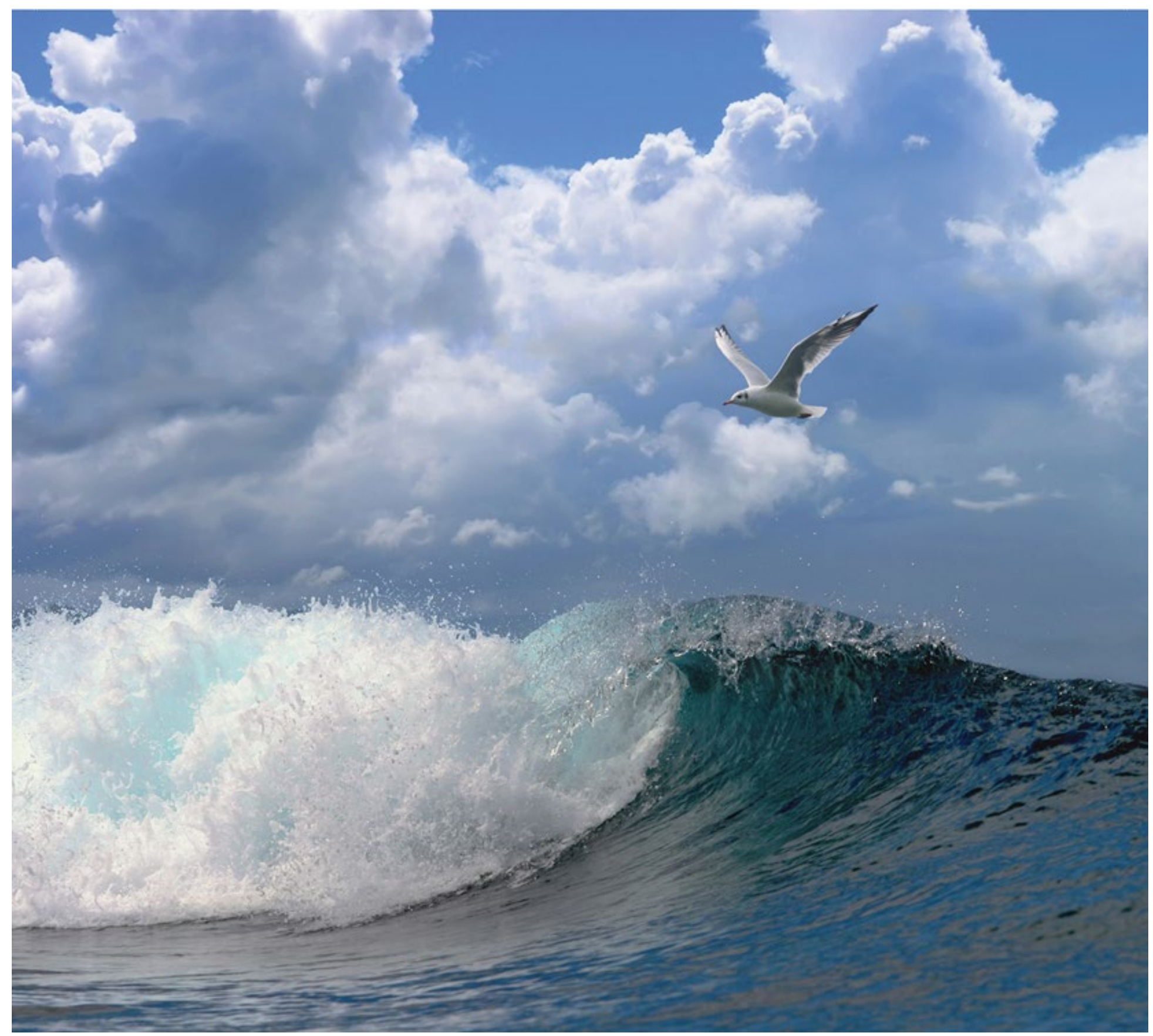

Fishing activity near Wintershall offshore pipelines 


\section{Fishing activity near Wintershall offshore pipelines}

Author(s): $\quad$ Niels Hintzen

Publication date: $30^{\text {th }}$ of July 2019 
Niels Hintzen, 2019. Fishing activity near offshore pipelines; . Wageningen, Wageningen Marine Research (University \& Research centre), Wageningen Marine Research report C073/19, 22 pp.; number of tables 6; ref. page 20.

Keywords: Offshore Pipeline; Trawling Fishery Factor; Risk- \& Probability Analysis.

This report can be downloaded for free from https://doi.org/10.18174/496892.

Wageningen Marine Research provides no printed copies of reports.

Client:

Client: IRM Systems

Maerten Trompstraat 25

2628 RC Delft

Wageningen Marine Research is ISO 9001:2015 certified.

\section{(C) Wageningen Marine Research}

Wageningen Marine Research, an institute Wageningen Marine Research accepts no liability for consequential damage, nor within the legal entity Stichting for damage resulting from applications of the results of work or other data Wageningen Research (a foundation under obtained from Wageningen Marine Research. Client indemnifies Wageningen Dutch private law) represented by Dr. Marine Research from claims of third parties in connection with this application. M.C.Th. Scholten, Managing Director All rights reserved. No part of this publication may be reproduced and / or

KvK nr. 09098104, published, photocopied or used in any other way without the written permission WMR BTW nr. NL 8113.83.696.B16. Code BIC/SWIFT address: RABONL2U IBAN code: NL 73 RABO 0373599285 


\section{Contents}

$\begin{array}{lr}\text { Summary } & 4\end{array}$

1 Introduction $\quad 5$

2 Assignment $\quad 6$

$3 \quad$ Materials and Methods $\quad 7$

$4 \quad$ Results $\quad 12$

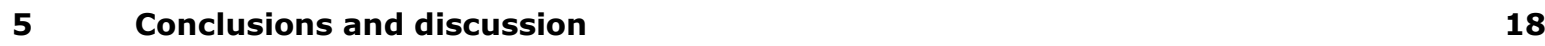

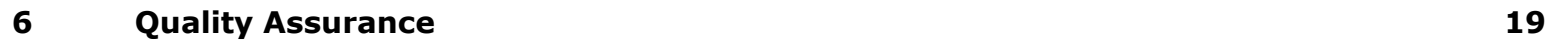

$\begin{array}{lr}\text { References } & 19\end{array}$

$\begin{array}{lr}\text { Justification } & \mathbf{2 1}\end{array}$ 


\section{Summary}

On the North Sea bottom lie numerous pipelines to link oil- or gas offshore units, - platforms and processing stations on land. Although pipeline tubes are coated and covered with protective layers (Concrete Weight Coating), the pipelines risk being damaged through man-made threats like fishing activities with bottom trawls (trawling interference), anchoring and dropped objects.

IRM Systems performs integrated risk assessments of pipelines for amongst others Wintershall. Spatial maps of fishing activity would contribute to this risk assessment. Therefore, WMR was tasked to quantify the amount of fishing activity in the vicinity of Wintershall pipelines. Fishing activity has been quantified at a spatial scale of approximate $2500 \mathrm{~m}^{2}$ blocks $(50 \mathrm{~m}$ by $50 \mathrm{~m}$ ) using fishing Vessel Monitoring System (VMS) data for 2016 and 2018. In total, for each year 69 shapefiles specifying the fishing intensity in a buffer area of $100 \mathrm{~m}$ either side of the pipeline, were delivered.

The overall total trawl fishing intensity in 2016 and 2018 along the pipeline trajectories ranges from 0 - 18.83 times per grid cell per year and is the result of combining all beam-trawl fleet activities, though split by large beam trawls and shrimp trawls. There is substantial difference in effort between 2016 and 2018 which varies up to $200 \%$ for some pipeline segments. Though, at the North Sea scale, fishing has been relatively stable over the past 10 years. Highest fishing intensities are recorded within the $12 \mathrm{~nm}$ zone where the effort of the shrimp trawlers is most abundant and has increased almost 5-fold in some areas from 2010 and has not come to a halt yet.

At the spatial scale relevant in this study, small spatial differences make for substantial differences though. 


\section{Introduction}

On the North Sea bottom lie numerous pipelines to link oil- or gas offshore units, - platforms and processing stations on land, usually protected by concrete covers or rock dumps. Although pipelines are coated and covered with protective layers (Concrete Weight Coating), the pipelines risk being damaged through man-made threats like fishing activities with bottom trawls (trawling interference), anchoring and dropped objects.

Although positions of most pipelines are known (position of older pipelines may be less accurate) a collision avoidance strategy of the fishing fleet is lacking. Over the past decades, around thirty hits by fishing gear were recorded in the North Sea that resulted in pipeline leaks. Each leak caused by a hit by fishing gear may be associated with substantial environmental and economic risks. Identifying these risks may therefore be important in the overall risk assessment of offshore oil- and gas production activities.

Identifying where fishing operations are most dominant around pipeline trajectories at the sea bottom can support additional and better targeted surveying operations to check the integrity of pipelines.

Survey results may, in combination with predicted risks of fishing impact, result in tailored approaches to further protect pipelines from impacts or improve the design and position of new pipelines.

IRM Systems (IRMS) requested WMR to investigate bottom fishing activity of the Dutch fishing fleet near all offshore Wintershall pipelines based on VMS (Vessel Monitoring by Satellite) information, giving information on the spatial and temporal distribution of fishing vessel activities.

This study provides maps of fishing intensities for 2016 and 2018 in a buffer area around the pipelines that can be used in a GIS application by IRMS to assess risks and advise Wintershall on Risk-Based survey frequencies. The addition of a fishing intensity layer to the procedure currently applied by IRMS Smart Pipeline Data may improve the overall risk assessment for pipeline damages. Moreover, the resolution used in this study would enable IRMS to execute the risk assessments with a relatively high precision. The accuracy of the data determines the final accuracy of the risk assessment. 


\section{Assignment}

Within this study, we quantify the amount of fishing effort that is allocated at, or close to, a selection of pipelines by Dutch bottom fishing vessels. In the quantification, measures of uncertainty in the data collected that represents fishing activity, are directly implemented. The final product are 69 shapefiles for each of the years 2016 and 2018, containing the pipeline trajectories including a buffer area, and the associated fishing intensity (i.e. number of times a specific grid cell is trawled) within these areas at a precision level of $2500 \mathrm{~m}^{2}(50 \mathrm{~m} * 50 \mathrm{~m})$ grid cells. 


\section{$3 \quad$ Materials and Methods}

Since the 1st of January 2005 all fishing vessels larger than 15 meters are equipped with VMS (Vessel Monitoring by Satellite) and since the 1st of January 2012 the on-board VMS-obligation concerns all vessels larger than 12 meters. A VMS transponder sends at regular intervals a signal to a satellite providing information on the vessel's ID, position, time and date, direction and speed. Hence, VMS is a useful data source to study the distribution of the fishing fleet both in time and space. The Dutch Ministry of Agriculture, Nature and Food Quality is tasked with the collection of VMS data of all Dutch fishing vessels. VMS data of foreign vessels, even inside the EEZ, are made irregularly available for scientific purposes. All VMS positions are collected in the WGS84 coordinate reference system.

As VMS signals lack any information on the activities of the fisheries itself, e.g. regarding fishing gear, catch composition, departure harbour or vessel dimensions, for many fisheries related studies, VMS is coupled to fisheries logbooks. These logbooks report per fishing trip (approx. 2 - 5 days) when fishermen leave harbour, what gear has been used to fish, their catch composition and a rough estimate of the location of the catches for each 24 hour period. Both VMS and logbook data report on the fishing vessel ID, which allows for the coupling of the two datasets and study fisheries distribution at finer spatial and temporal scales.

A summary of the VMS- data-processing starting with pre-process, analyse VMS- and logbook data, combine these datasets and link gear specific effort to the pipelines is given below. A more detailed description on the processing and assumptions made during this process can be found in Hintzen et al. (2013).

Data pre-processing:

- VMS and logbook data are received from the Ministry of Agriculture, Nature and Food Quality and stored in a local database at WMR.

- VMS records are considered invalid and therefore removed from the analyses when they:

$\circ \quad$ are duplicates or pseudo-duplicates (indication of malfunctioning of VMS device)

- identify an invalid geographical position

$\circ \quad$ are located in a harbour

- are located on land

- are associated with vessel speeds $>20$ knots

- Logbook records are removed from the analyses when they:

- are duplicates

- have arrival date-times before departure date-times

o overlap with other trips

Link VMS and logbook data:

- VMS and logbook datasets are linked using the unique vessel identifier and date-time stamp in both datasets available. In other words, records in the VMS dataset that fall within the departure-arrival timeframe of a trip described in the logbook are assigned the unique trip number from the logbook record which allows matching both datasets.

- $\quad$ Fishing trips, using beam trawl bottom gear types (traditional beam trawling, pulse trawling and shrimp trawling), showing VMS signals around the pipelines track [between latitudes 52.29 and 55.9; longitudes 2.6 and 4.85] are selected (gears such as otter trawls, gillnets or midwater trawls are not taken into account given their limited width, or non-existing contact with the seabed when in operation).

- Only VMS and logbook data for the entire years 2016 and 2018 are used, as to present variability over years. 
Define fishing activity:

- Speed recordings obtained from VMS data are used to create frequency plots of these speeds, where along the horizontal axis the speed in knots is given and the vertical axis denotes the number of times that speed was recorded. In general, 3 peaks can be distinguished in such a frequency plot. A peak near 0 knots, associated with being in harbour/floating, a peak around the average fishing speed and a peak around the average steaming speed. These analyses are performed separately per gear type for two kW classes ( $<=225 \mathrm{~kW}$ and $>225 \mathrm{~kW}$ ) as these vessel types show different fishing behaviour and are allowed to fish in different regions.

- According to the method described above, a number of VMS records can be associated with fishing activity, depending on the gear used by the vessel. In general, vessel speeds between 1.5 and 8 knots are characterized as fishing. For small beam trawlers the selected range was approximately 2-7 knots. For large trawlers the range was approximately 4-8 knots.

Increase spatio-temporal resolution:

- VMS recordings are available for fishing vessels approximately every two hours down to 30 minutes in more recent years. When the vessel speed is 4 knots, the trawling distance between two successive VMS locations, at 2 hour pings intervals, is approximately $15 \mathrm{~km}$. Although on a yearly basis this amounts to a vast amount of spatial data, for studies such as the current one, additional detail is required to appropriately link a pipeline route to crossing fishing vessels activities. For this purpose, an interpolation routine is used which estimates intermediate locations between two successive VMS pings. The routine used in this study is described in detail in Hintzen et al., 2010. On average, an additional 700 points are added in between two successive VMS pings which are by default two hours apart, resulting in a dataset with pings intervals of 10 seconds.

Define area of interest:

- In total $426 \mathrm{~km}$ pipeline trajectories were identified that needed investigation in this study (see Figure 1). The study area has further been divided into small squares (a grid) of $\sim 50 \times 50 \mathrm{~m}$ blocks to allow for more detailed spatial analyses (0.00077 degrees longitude by 0.00045 degrees latitude). 


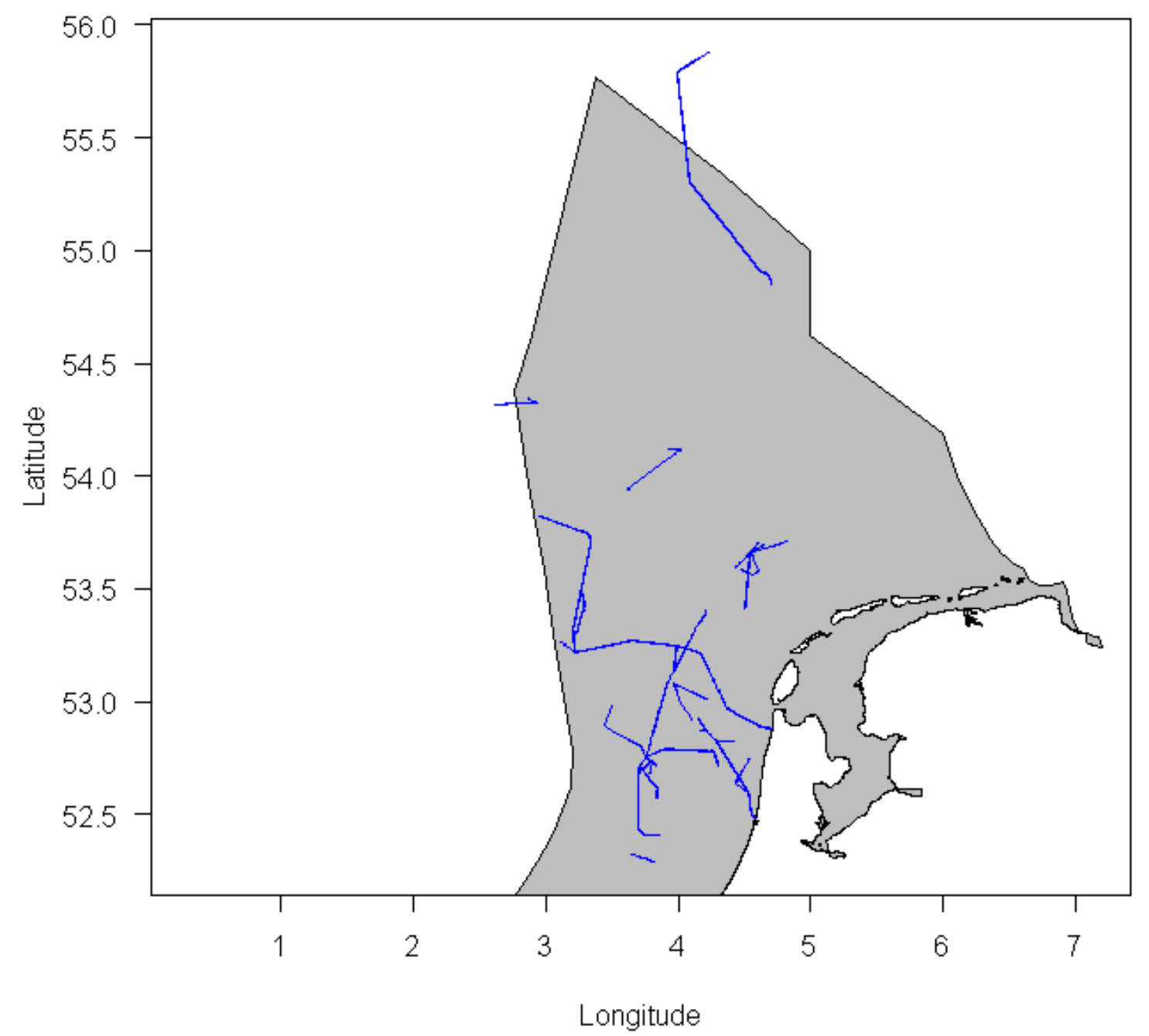

Figure 1. Dutch North Sea coast and locations of pipelines included a buffer area (100m either side) around pipelines

Link pipeline location to fishing effort:

- We assume that a pipeline hazard may be caused by a build-up of smaller damage events caused by passages of active fishing vessels using bottom gears. The exact route of fishing vessels is however uncertain given that only every 2 hours exact vessel position data is collected. Therefore, an increased spatio-temporal resolution improvement was applied(see above) based on interpolation. This however, does not account for uncertainty in the interpolation method. Therefore, additionally we assume that activity is certain at the locations from which a VMS ping was send to the satellite, but certainty decreases in between these time stamps and decreases further away from the interpolated track. This together creates a 2-dimensional confidence interval for each fishing vessel movement, which can be scaled to represent 2 hours of fishing in total. Figure 2 gives a graphical representation of the interpolation and confidence interval calculation.

Note that each grid cell then represents a certain amount (measured in ${ }^{\circ}$ minutes) of fishing activity. This uncertainty is calculated assuming a grid of 50x50m blocks. By cumulating the fishing effort of all vessels of the fleet under consideration, the grid cell values reveal detailed spatial information of fishing activities during a year. By multiplying the fishing activity by gear with, and dividing by surface area of each grid cell, we calculate the fishing intensity.

Fishing intensity (FI) in a grid cell $g$ in year $y$ is calculated as:

$$
F I_{g, y}=\sum_{1: n}^{i} \frac{\text { Effort }_{i, g, y} * \text { Speed }_{i, y} * \text { GearWidth }_{i}}{\text { surfaceArea }_{g}}
$$


Finally, the pipeline location is overlaid onto the fishing activity grid to link the fishing effort to each pipeline location. A shape file is created containing the fishing activity by grid cell bounded by the pipeline trajectories.

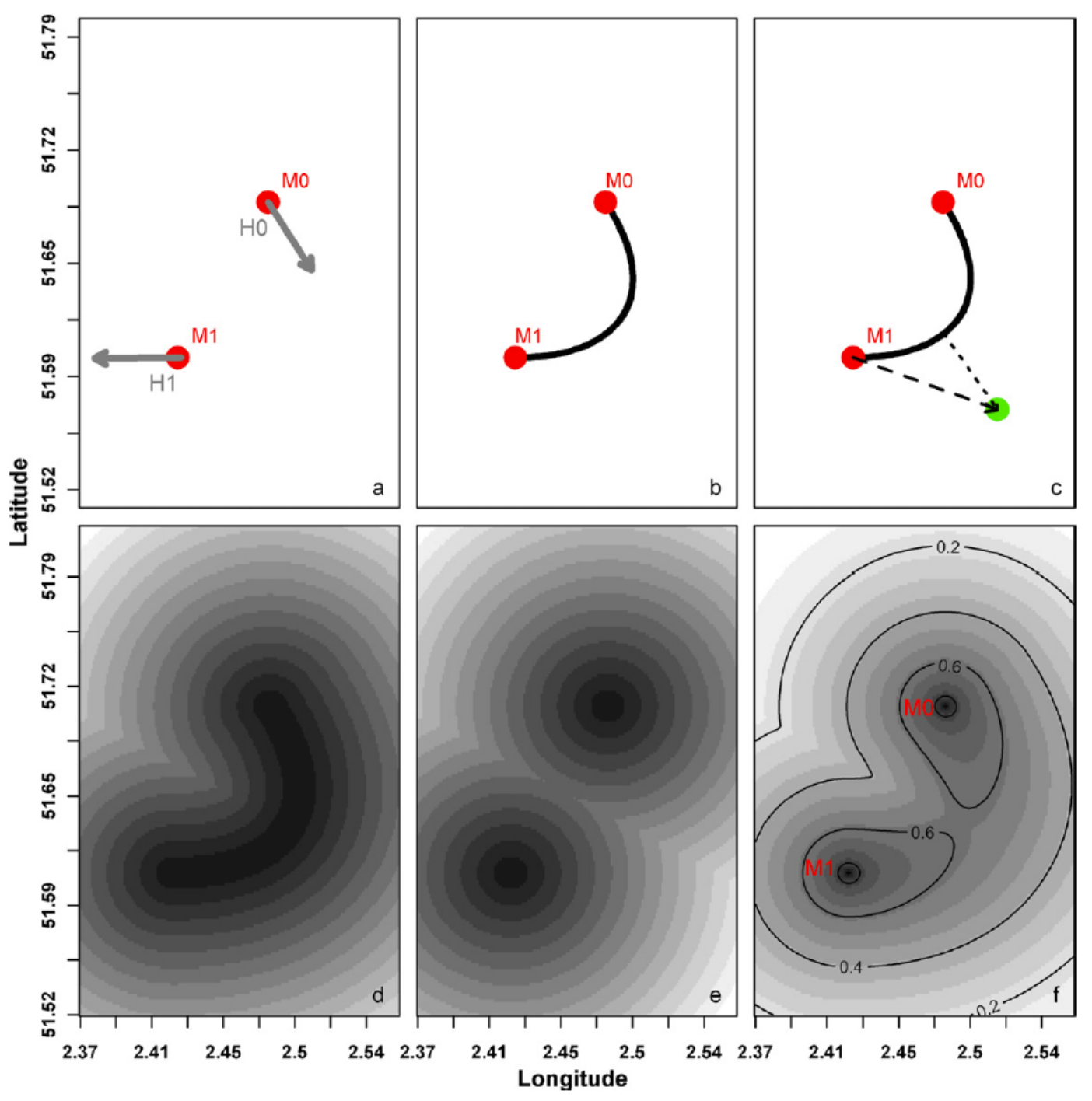

Figure 2. Schematic representation of the interpolation process starting with two succeeding VMS position registrations towards an estimated track surrounded by a confidence interval. See Hintzen et al. 2010 for further technical details. (a) The start and end point of the vessel are represented by $M_{0}$ and $M_{1}$ respectively, the heading of the vessel at start- and end-point are represented by the small arrows $\mathrm{H}_{0}$ and $\mathrm{H}_{1}$. Based on the value of a scaling parameter these arrows become longer/shorter influencing the curvature of the interpolation (see panel b). For small values of this parameter, the interpolation will approximate a straight line between $M_{0}$ and $M_{1}$. (b) Interpolated track based on cubic Hermite spline (black solid line). (c) distance from each random point on a grid to (e.g.green dot) depends on the distance marked by the dashed arrow (black dashed arrow) from M1 to the green dot. (d) Shortest distance from each point on a grid to the interpolated track. Lighter grey represents more distant grid cells. (e) Shortest distance from each point on a grid to either Mo or M1. Lighter grey represents more distant grid cells. ( $f$ ) Interpolation between two succeeding VMS data points surrounded by a confidence interval representing chance of fishing in a grid cell. At positions MO and M1, values equal one.

In this study, only beam trawl gears were taken into account as these are expected to have the largest impact on pipelines due to the design of the gear with either $12 \mathrm{~m}$ wide steel beams or wings. Other gears, such as otter trawls are expected to have a limited impact as the boards themselves are only a couple of $\mathrm{cm}$ wide. The Dutch fleet consists of $\sim 80$ vessels fishing outside the $12 \mathrm{~nm}$ zone with beam trawls on demersal fish, another $\sim 40$ vessels, that operate $4.5 \mathrm{~m}$ beams on either side, are 
allowed inside the $12 \mathrm{~nm}$ zone as well and 180 vessels operate a lighter shrimp oriented beam trawl gear inside the $12 \mathrm{~nm}$. In this study we analyse the beam trawls on demersal fish and shrimp separately as the latter group has a markedly lighter gear. Specifics on gear design and impact can be found in Eigaard et al. 2016

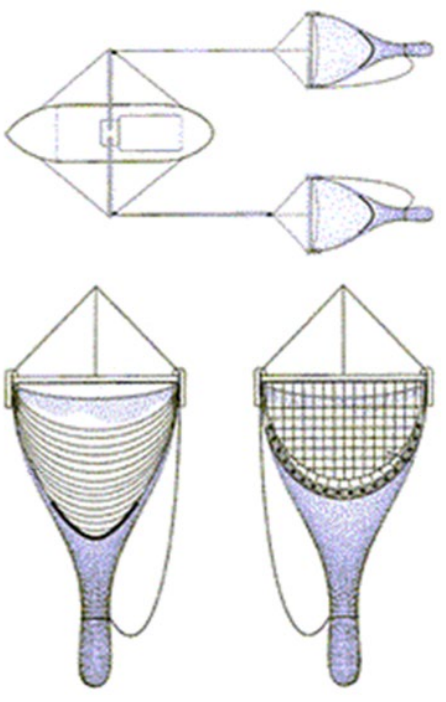

Beam trawls

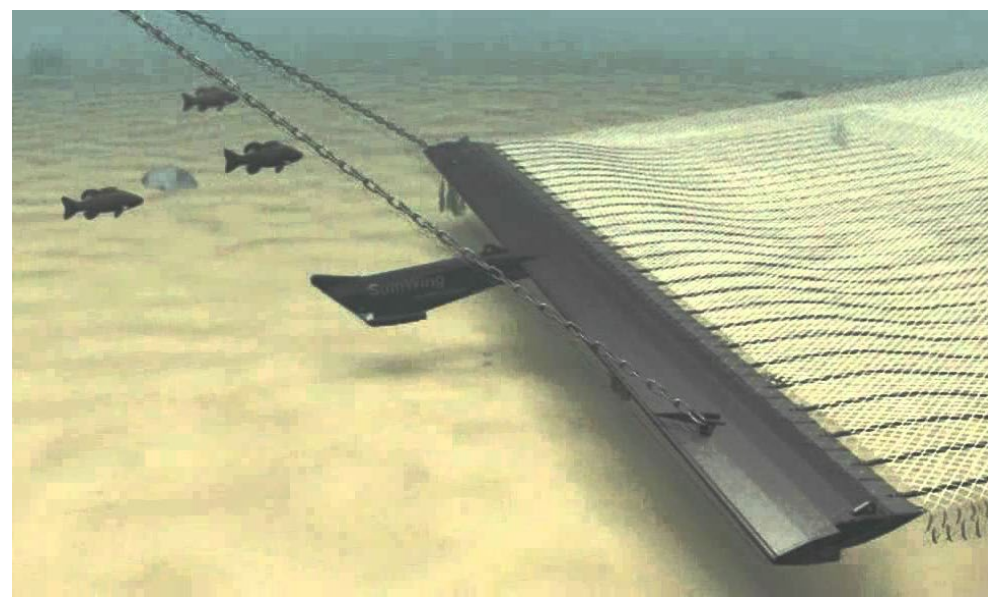

Figure 3(left): Design of beam trawl gear in which a steel beam of $12 \mathrm{~m}$ wide $(4.5 \mathrm{~m}$ for smaller vessels) is pulled forward, gliding on 'shoes' that are mounted either side of the beam. Behind the beam, tickler chains are mounted (or wires emitting pulses) that ensure that sole and or plaice are triggered out of the seabed into the fishing gear. Figure from Eigaard et al. 2016. (right) The beam design has in recent years on some vessels been replaced by a wing-design (see www.sumwing.nl and https://library.wur.nl/WebQuery/wurpubs/fulltext/349508) 


\section{$4 \quad$ Results}

The area of interest and pipeline trajectories, as provided by IRMS, is shown in Figure 1.

Figure 4 below shows the effort of the entire Dutch fleet (including non-beam trawl fisheries) over the past 10 years with the Wintershall pipelines projected on top. The majority of the pipelines are in areas with relatively low fishing effort and even pipelines with a coastal connection are exposed to limited effort. The most northerly pipelines are exposed to almost no fishing effort.

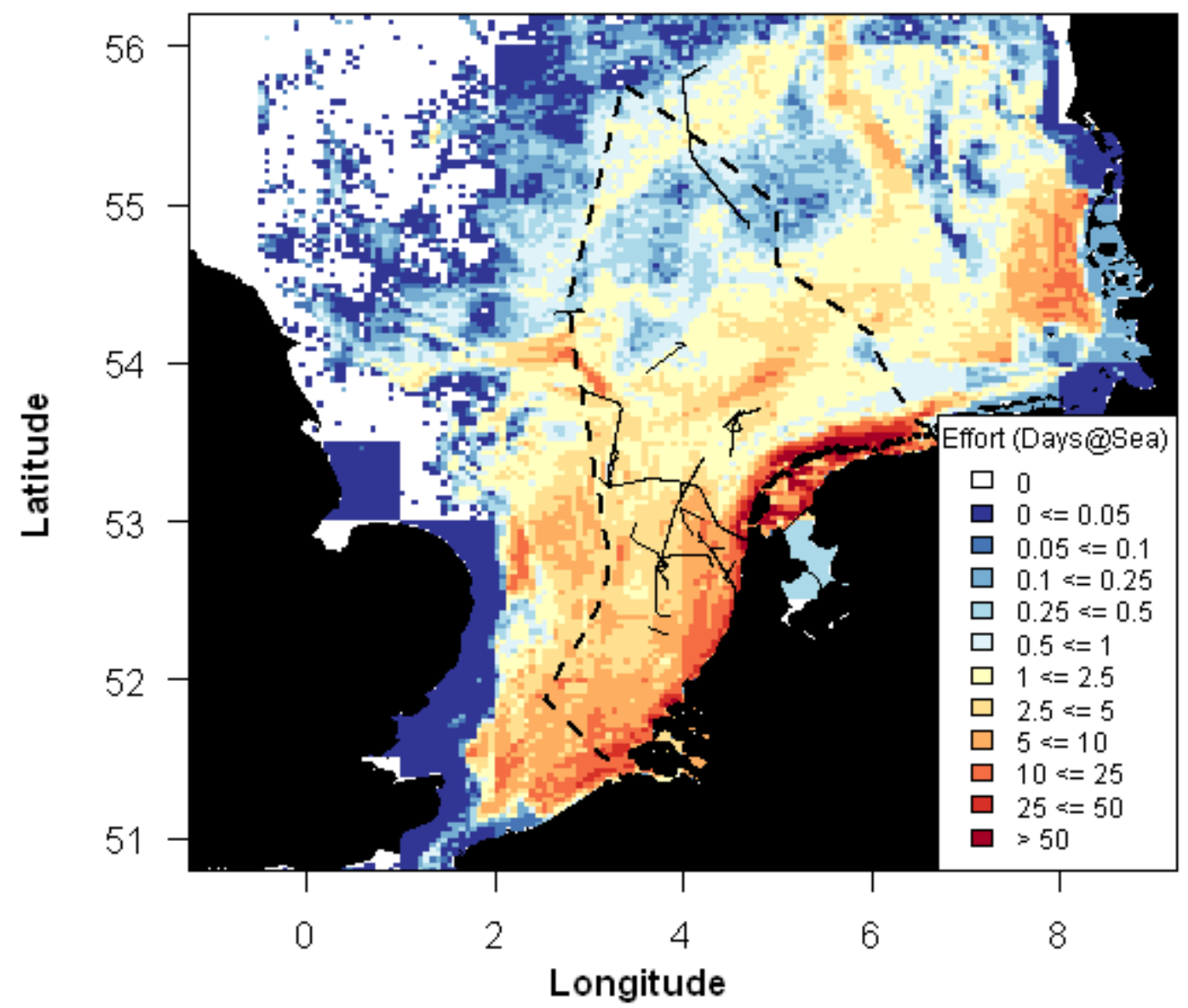

Figure 4. Fishing effort (in Days@Sea) for the entire Dutch fishing fleet over the past 10 years at 1 minute grid cell resolution. The Wintershall pipelines are overlaid in black. Note that this map is based on different data than used for the analyses of fishing impact on pipelines in this study.

Figure 4 is based on VMS positions only, and hence do not suffice in the need to estimate fishing activity at very small spatial scales such as 50 by $50 \mathrm{~m}$ blocks. To illustrate the difference in interpretation, Figure 5 below shows fishing intensity estimated from raw VMS pings, interpolated fishing tracks and fishing tracks associated with uncertainty. 


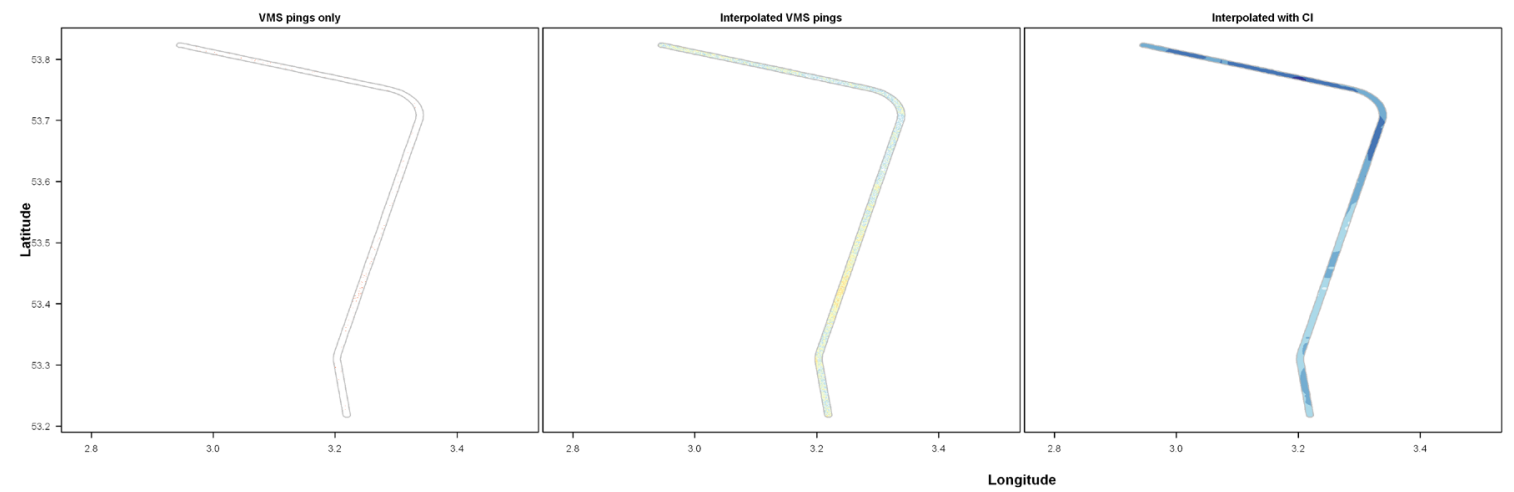

Figure 5. Gridded (at 50m x 50m squares) fishing effort as derived from VMS pings only (left hand panel), interpolated fishing tracks (middle panel) and interpolated fishing tracks including uncertainty estimate (right hand panel) for pipeline segment W10, including the buffer area. Left-hand figure indicates very patchy fishing effort due to the temporal patchiness of the data. Middle panel shows some higher intensities (yellow areas) vs completely empty cells (in white) while the right-hand panel shows more evenly distributed fishing effort without empty cells.

The results in Figure 5 clearly indicate that both VMS pings (left panel) and interpolated tracks (middle panel) result in predominantly presence vs abundance only along the pipeline while including the uncertainty estimate gives a smoothed view of fishing intensity (right panel). The results should hence be interpreted accordingly: smooth results are not identical to realisations, i.e. not the entire pipeline has been crossed during fishing events.

The overall total trawl fishing intensity in 2016 and 2018 along the pipeline trajectory ranges from 0 18.83 times per grid cell per year and is the result of combining all beam-trawl fleet activities, though split by large beam trawls and shrimp trawls. Shrimp trawls have a lighter gear and hence the expected impact of the gear is lower than of beam-trawls fishing for demersal fish. The spatial distribution by beam-trawl effort depends on the vessel size. The smaller beam-trawl vessels are active within the $12 \mathrm{~nm}$ coastal zone while larger beam-trawlers are banned from this area.

Figure 6 and 7 below illustrate the fishing intensity (number of times a grid cell has been trawled per year) of both small (shrimp beam trawl) and large (all other beam trawl) vessels in two selected pipeline segments, one far off-shore and one close to shore.

W03 2016 Large vessels

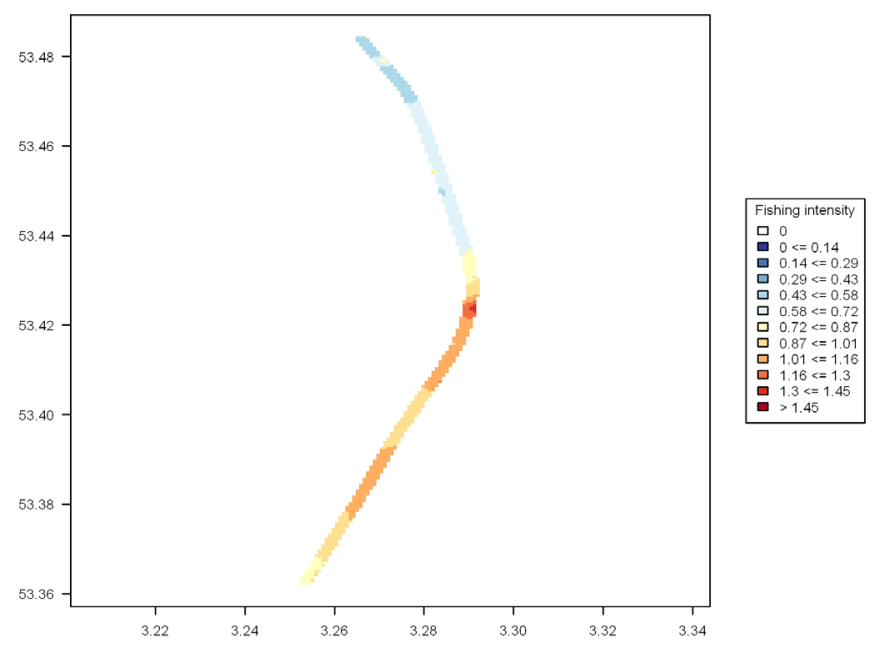

Figure 6. Fishing intensity of a pipeline sector far offshore (close to EEZ border) with only large beam trawling activity in the vicinity of the pipeline. 


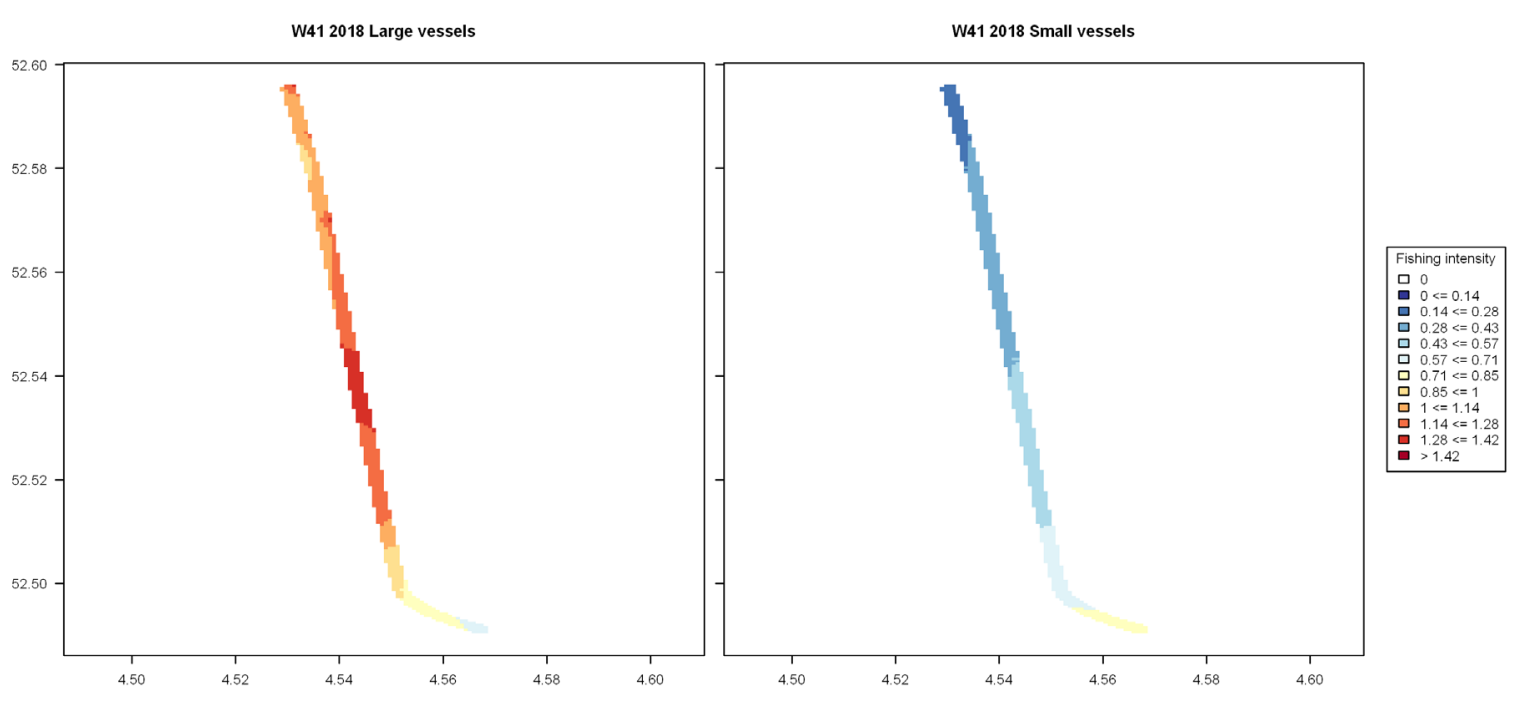

Figure 7. Fishing intensity of a pipeline sector connected to shore with both large beam trawling activity outside of the $12 \mathrm{~nm}$ zone (ending around 4.55 degrees longitude) and shrimp beam trawling especially inside the $12 \mathrm{~nm}$ zone.

Fishing effort in the entire North Sea has been stable between 2016 and 2018. The variability between years in fishing activity in the vicinity of the pipelines is however much larger. Table 1 below shows the median and maximum percentage difference in fishing intensity along a pipeline segment. Table 2 shows the relative difference in fishing intensity change (each grid cell is scaled by pipeline segment mean value and compared between 2016 and 2018). The absolute difference is substantial in several areas while the relative difference is on average much smaller for both the large and small vessels (See Figure 8 for a graphical illustration). This can be explained by the increasing number of vessels that move further south in the North Sea to target especially Sole. 
Table 1. Absolute differences in fishing intensity between 2016 and 2018 in percentages. Values close to 0 denote no difference while values > 0 indicate larger effort in 2018 than in 2016 and vice versa. W01 W72 denote the pipeline segment.

\begin{tabular}{|c|c|c|c|c|}
\hline & $\begin{array}{l}\text { Median difference } \\
\text { Large vessels (\%) }\end{array}$ & $\begin{array}{c}\text { Maximum } \\
\text { difference Large } \\
\text { vessels }(\%)\end{array}$ & $\begin{array}{l}\text { Median difference } \\
\text { Small vessels }(\%)\end{array}$ & $\begin{array}{c}\text { Maximum } \\
\text { difference Small } \\
\text { vessels }(\%)\end{array}$ \\
\hline W01 & -58 & -54 & 0 & 0 \\
\hline W02 & -11 & 44 & 0 & 0 \\
\hline W03 & -39 & -4 & 0 & 0 \\
\hline W04 & -23 & 10 & 0 & 0 \\
\hline W05 & -30 & -24 & 0 & 0 \\
\hline W06 & -32 & -26 & 0 & 0 \\
\hline W07 & -46 & -33 & 0 & 0 \\
\hline W08 & -21 & -2 & 0 & 0 \\
\hline W09 & -64 & 72 & -94 & -92 \\
\hline W10 & -52 & 123 & 0 & 0 \\
\hline W11 & 7 & 60 & 0 & 0 \\
\hline W12 & 48 & 245 & 0 & 0 \\
\hline W13 & 48 & 245 & 0 & 0 \\
\hline W14 & 47 & 407 & 0 & 0 \\
\hline W15 & 47 & 407 & 0 & 0 \\
\hline W16 & -61 & -38 & 0 & 0 \\
\hline W17 & -58 & -15 & 0 & 0 \\
\hline W18 & -57 & -12 & 0 & 0 \\
\hline W19 & -9 & 27 & 0 & 0 \\
\hline W20 & -29 & 131 & 108 & 631 \\
\hline W21 & -26 & 185 & 0 & 0 \\
\hline W22 & -26 & 185 & 0 & 0 \\
\hline W23 & 0 & 71 & -53 & -51 \\
\hline W24 & -4 & 71 & -70 & -68 \\
\hline W25 & -12 & 98 & 0 & 0 \\
\hline W26 & -13 & 33 & 0 & 0 \\
\hline W27 & -11 & -6 & 0 & 0 \\
\hline W28 & -34 & -27 & 0 & 0 \\
\hline W29 & -21 & -8 & 0 & 0 \\
\hline W30 & -29 & -6 & 0 & 0 \\
\hline W31 & -53 & 12 & 0 & 0 \\
\hline W32 & -53 & 12 & 0 & 0 \\
\hline W33 & -28 & 76 & 0 & 0 \\
\hline W34 & -48 & -35 & 0 & 0 \\
\hline W35 & -55 & -16 & 0 & 0 \\
\hline W36 & -15 & 36 & -10 & -8 \\
\hline W37 & 3 & 25 & -24 & -16 \\
\hline W38 & 5 & 84 & -24 & -22 \\
\hline W39 & 206 & 461 & 1 & 9 \\
\hline W40 & 204 & 467 & -3 & 4 \\
\hline W41 & 78 & 144 & 94 & 123 \\
\hline W41 & 69 & 712 & 16 & 54 \\
\hline W42 & 58 & 85 & 6 & 39 \\
\hline W43 & 133 & 940 & 0 & 0 \\
\hline W43 & 21 & 1140 & 0 & 0 \\
\hline W44 & 133 & 927 & 0 & 0 \\
\hline W44 & 25 & 1151 & 0 & 0 \\
\hline W45 & - & - & 0 & 0 \\
\hline W46 & - & - & 0 & 0 \\
\hline W47 & -30 & -12 & 0 & 0 \\
\hline W48 & -53 & -14 & 0 & 0 \\
\hline W49 & -17 & 63 & 0 & 0 \\
\hline W50 & - & - & 0 & 0 \\
\hline W51 & -56 & -51 & 0 & 0 \\
\hline W52 & 110 & 210 & 0 & 0 \\
\hline W53 & 110 & 210 & 0 & 0 \\
\hline W54 & 11 & 18 & -46 & -46 \\
\hline W55 & -30 & -12 & 0 & 0 \\
\hline
\end{tabular}




\begin{tabular}{|l|c|c|c|c|}
\hline W57 & -17 & 38 & 0 & 0 \\
\hline W62 & -48 & -35 & 0 & 0 \\
\hline W63 & -28 & 76 & 0 & 0 \\
\hline W64 & -55 & -16 & 0 & 0 \\
\hline W65 & -11 & -6 & 0 & 0 \\
\hline W66 & -34 & -27 & 0 & -22 \\
\hline W67 & 5 & 84 & -24 & 0 \\
\hline W69 & 82 & 589 & 0 & 0 \\
\hline W70 & 82 & 589 & 0 & 0 \\
\hline W71 & 82 & 589 & 0 & 0 \\
\hline W72 & - & - & 0 & \\
\hline
\end{tabular}



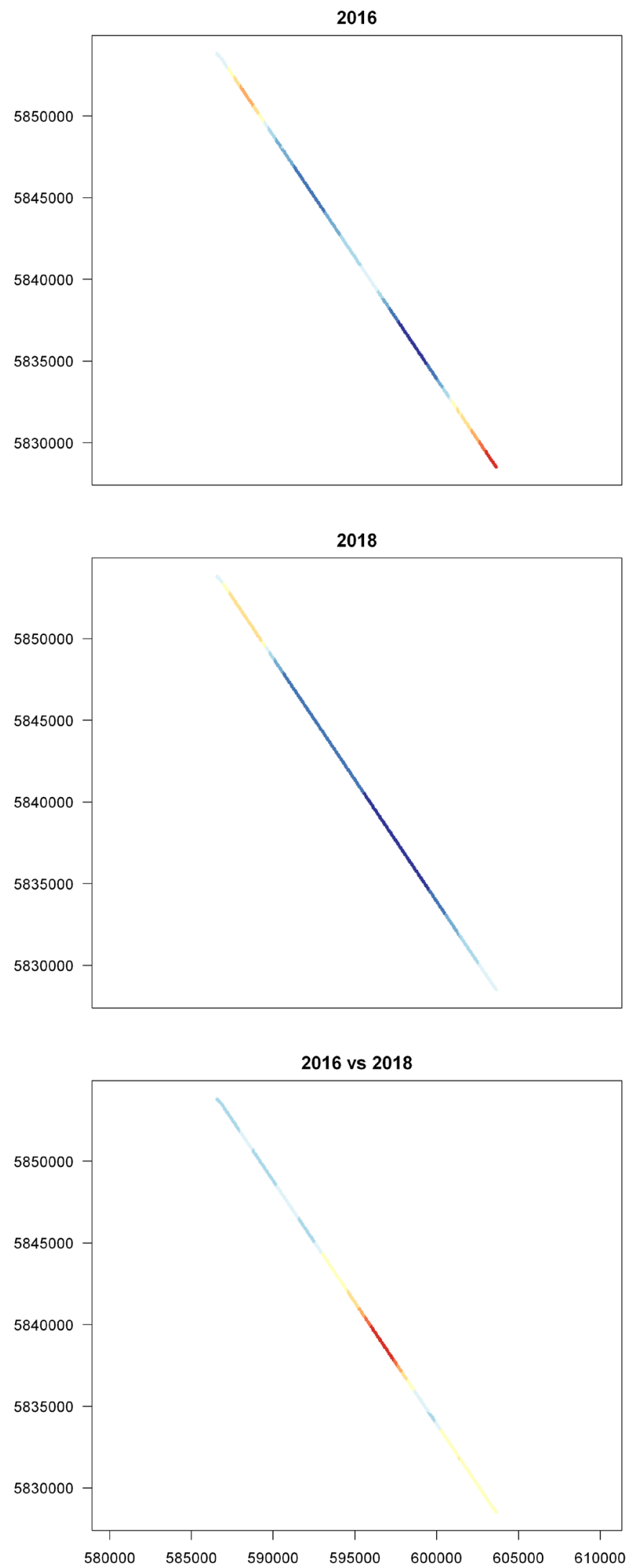

Figure 8. Estimated fishing intensity for segment W41A in 2016, 2018 and the relative difference between 2016 and 2018. Note that the top and middle panel are on the same colour scale but that the bottom panel shows the areas in red that are relatively less fished in 2018 compared to 2016 and in dark blue areas that are relatively more fished in 2018 than in 2016. 


\section{$5 \quad$ Conclusion and discussion}

\section{Concluding:}

The overall total trawl fishing intensity in 2016 and 2018 along the pipeline trajectory ranges from 0 18.83 times per grid cell per year and is the result of combining all beam-trawl fleet activities, though split by large beam trawls and shrimp trawls. There is substantial difference in effort between 2016 and 2018 which varies up to $200 \%$ for some pipeline segments. Though, at the North Sea scale, fishing has been relative stable over the past 10 years

(https://www. agrimatie. $\mathrm{nl} /$ PublicatiePage. aspx?subpubID $=2526 \&$ sectorID $=2862 \&$ themaID $=2858$ \&indi catorID\%20=\%202880). On a broader scale, highest fishing intensities are recorded within the $12 \mathrm{~nm}$ zone where the effort of the shrimp trawlers is most abundant and has increased almost 5-fold in some areas from 2010 and has not come to a halt yet (Hintzen et al 2017).

At the spatial scale relevant in this study, small spatial differences make for substantial differences though.

\section{Discussion:}

Fishers who used to fish with large beam-trawls have switched to new innovative gear types which weigh less and partially hoover over the seabed (pulse trawl, sumwing). These gears have only recently been introduced and new fishing grounds are being explored by the fishers. Sumwing were used from 2010 to 2018 and the fishing effort of pulse trawls started in 2010 and gradually increased specially for the large trawlers fishing outside the 12 mile zone. Small trawlers use mainly traditional beam trawlers. It is unknown however how the change in gear design affects impact on pipelines. The angle at which pipelines are crossed is also likely associated with a different impact, with a clear north-south direction in the southern North Sea and more random in the Northern parts. In this analysis however, all types of fishing activity in the vicinity of the pipelines were taken into account. Indicators tailored to take direction of crossings into account could be obtained when using AIS data (Automatic Identification System, a GPS transponder on-board fishing vessels transmitting a signal every 2-3 seconds), which provides fishing activity information every 2-3 seconds. Using all available AIS data though will result in more precise spatio-temporal estimates of fishing activity around pipelines. Further in-depth analyses would require however high spatio-temporal data such as AIS, to study with more precision the exact fishing trawl tracks. One of the major drawbacks of AIS is, however, the lack in temporal coverage. Previous analyses by the authors indicated that in over $50 \%$ of fishing trips, AIS was turned off. Fishermen are, by law, allowed to turn AIS off if turning it off results in a safer environment for the fishermen. In all other occasions, it is obligatory to have AIS turned on. It is unknown how controlling agencies enforce that AIS is only turned off under dangerous situations. Overall, bias in effort could easily be introduced when measures to account for lack of AIS data are not incorporated.

Given the unavailability of AIS data, for this study we had to rely on the relatively low temporal resolution provided by VMS (one ping every 15 to 120 minutes) which did limit the accuracy of our analyses. Using interpolation and confidence interval techniques did improve the understanding of fishing intensity around pipelines. The uncertainty related to the long interval rate between successive VMS pings is directly taken into account, here by making use of a confidence interval around potential fishing tracks. This results in a smoothed pattern of fishing impact on all pipeline segments, while realized fishing intensity around the pipelines will be more scattered but the exact location unknown. Especially under longer time-periods, the realized fishing intensity and approximation shown in this report will converge however. The interpretation of fishing intensity related to risk should be taken with care. Even though it is likely that fishing intensity and pipeline damages are strongly related, VMS or other spatial data such as AIS do not prove that only vessel presence has led to pipeline damages, as other (environmental or human) factors may cause damages as well. 


\section{Quality Assurance}

Wageningen Marine Research utilises an ISO 9001:2015 certified quality management system. This certificate is valid until 15 December 2021. The organisation has been certified since 27 February 2001. The certification was issued by DNV GL. 


\section{References}

Eigaard, O. R., Bastardie, F., Breen, M., Dinesen, G. E., Hintzen, N. T., Laffargue, P., Mortensen, L. O., et al. 2016. Estimating seabed pressure from demersal trawls, seines, and dredges based on gear design and dimensions. ICES Journal of Marine Science, 73: i27-i43.

Hintzen, N. T., Piet, G. J., and Brunel, T. 2010. Improved estimation of trawling tracks using cubic Hermite spline interpolation of position registration data. Fisheries Research, 101: 108-115.

Hintzen, N.T. Coers, A., Hamon, K. (2013) A collaborative approach to mapping value of fisheries resources in the North Sea (Part 1: Methodology). http://edepot.wur.nl/248628.

Tien, N., Hintzen, NT., Verkempynck, R., Kraan, M., Trapman, B., Craeymeersch, J., Van Asch, M., 2017. De bodemberoerende visserij in de Voordelta sinds 2004.

https://library.wur.nl/WebQuery/wurpubs/fulltext/429215 


\section{Justification}

Report C073/19.

Project Number: 4311100103.

The scientific quality of this report has been peer reviewed by a colleague scientist and a member of the Management Team of Wageningen Marine Research

[Make sure that the internal review is arranged in the early stages of the project (an independent, critical expert. The chosen reviewer will be authorised by the responsible management team member on the moment of approving the final document.]

Approved: $\quad$ Robbert Jak

Researcher

Signature:

Date: $\quad 30$ July 2019

Approved: $\quad$ Drs. J. Asjes

Manager Integration

Signature:

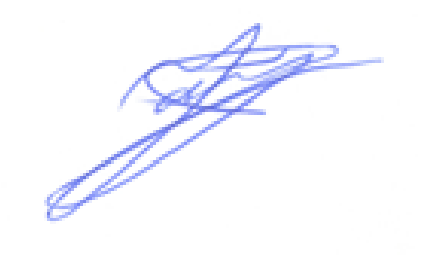

Date:

30 July 2019 
Wageningen Marine Research

$\mathrm{T}+31(0) 317480900$

E: marine-research@wur.nl

www.wur.eu/marine-research

Visitors' address

- Ankerpark 271781 AG Den Helder

- Korringaweg 5, 4401 NT Yerseke

- Haringkade 1, 1976 CP IJmuiden
Wageningen Marine Research is the Netherlands research institute established to provide the scientific support that is essential for developing policies and innovation in respect of the marine environment, fishery activities, aquaculture and the maritime sector.

\section{Wageningen University \& Research:}

is specialised in the domain of healthy food and living environment.

\section{The Wageningen Marine Research vision}

'To explore the potential of marine nature to improve the quality of life'

\section{The Wageningen Marine Research mission}

- To conduct research with the aim of acquiring knowledge and offering advice on the sustainable management and use of marine and coastal areas.

- Wageningen Marine Research is an independent, leading scientific research institute

Wageningen Marine Research is part of the international knowledge organisation Wageningen UR (University \& Research centre). Within Wageningen UR, nine specialised research institutes of the Stichting Wageningen Research Foundation have joined forces with Wageningen University to help answer the most important questions in the domain of healthy food and living environment. 